\title{
Intraspecific Variation of the Volatile Chemical Composition of Myracrodruon urundeuva Fr. Allem. ("Aroeira-do-Sertão"): Characterization of Six Chemotypes
}

\author{
Nayara Coriolano de Aquino, ${ }^{a}$ Renata Mendonça Araújo ${ }^{b}$ and \\ Edilberto Rocha Silveira*,a \\ ${ }^{a}$ Departamento de Química Orgânica e Inorgânica, Universidade Federal do Ceará, \\ 60021-940 Fortaleza-CE, Brazil \\ ${ }^{b}$ Instituto de Química, Universidade Federal do Rio Grande do Norte, \\ 50078-970 Natal-RN, Brazil
}

\begin{abstract}
Myracrodruon urundeuva Fr. Allem. (Anacardiaceae) is the scientific designation of "aroeira-do-sertão", a tree well dispersed through the "Caatinga", the characteristic northeastern Brazil flora. Its trunk bark decoction is used to treat cutaneous affections, urinary and respiratory diseases and as a postpartum aseptic bath. This work reports the analyses of the essential oils from leaves of 62 specimens of "aroeira-do-sertão". Analyses by ${ }^{1} \mathrm{H}$ nuclear magnetic resonance (NMR) and gas chromatography coupled to mass spectrometry (GC-MS) of all oil samples permitted the characterization of all major components and, in consequence, the characterization of six different chemotypes of $M$. urundeuva, represented by the chemomarkers: myrcene, $\alpha$-pinene, limonene, $\Delta^{3}$-carene, $(Z)$ and $(E)$ - $\beta$-ocimene.
\end{abstract}

Keywords: Myracrodruon urundeuva, essential oil composition, chemotype marker monoterpenes, intraspecific variation

\section{Introduction}

Myracrodruon urundeuva Fr. Allem. (Anacardiaceae, synonym: Astronium urundeuva) is a tree widely found in "Caatinga" and other dry forests of Brazil, from Ceará to Paraná states, especially on west of Bahia, Minas Gerais and São Paulo, as well as on south of Mato Grosso do Sul, Mato Grosso, and Goiás. ${ }^{1}$ Although present in these areas, this plant is more abundant in the northeast of the country where it is popularly known as "aroeira-do-sertão" or "aroeira", short for "araroeira" which means macaws's tree. Among other applications, its stem bark decoction has shown medicinal and ethnopharmacological properties on treating skin, respiratory, and urinary diseases, being also notorious as an aseptic bath for postpartum inflammation and other gynecological problems. ${ }^{2,3}$ Braga $^{4}$ reported the use of aroeira's stem bark on tanning industry due to its high tannin content. The bark or the light yellow resin obtained from the bark lesions are also widely used by the peasants as tonic. Its wood is used in civil construction as studs,

*e-mail: edil@ufc.br railroad ties, mills, beams, posts and hydraulic works, being almost imputrescible in contact with the ground.

Previous studies about the chemical composition of essential oils from M. urundeuva show divergent results. Analysis of the essential oils from dried leaves of "aroeirado-sertão" was performed by Maia et al..$^{5}$ Two different specimens, one collected in Maranhão state, and another in Tocantins state, presented the monoterpene $\Delta^{3}$-carene as its major chemical constituent (78.1 and $56.3 \%$, respectively). ${ }^{5}$ The essential oil from leaves of $M$. urundeuva analyzed by Montanari et al. ${ }^{6}$ also showed $\Delta^{3}$-carene as the major constituent $(78.8 \%)$. Figueredo et al..$^{7}$ analyzed the essential oil from fresh leaves of a specimen of "aroeirado-sertão" collected in Ceará state, the study showed the $\Delta^{3}$-carene as its major chemical constituent $(80.4 \%)$ and this essential oil showed antibacterial action.

In this work, essential oils from leaves of 62 individual wild specimens of "aroeira-do-sertão" collected in the states of Ceará (CE), Piauí (PI), Rio Grande do Norte (RN), Bahia (BA) and Pernambuco (PE) were analyzed and characterized through nuclear magnetic resonance (NMR) and gas chromatography coupled to mass spectrometry (GC-MS). 


\section{Experimental}

\section{Plant material}

The leaves of $M$. urundeuva were collected for 5 years, in the states of Ceará (32), Piauí (05), Rio Grande do Norte (17), Bahia (4) and Pernambuco (4). The georeferencing (GPS) data of each collection site is provided in Table S1 (Supplementary Information). A voucher specimen used for comparison (No. 48904) has been deposited at the Herbário Prisco Bezerra (EAC) of the Departamento de Biologia, Universidade Federal do Ceará, Fortaleza, Ceará, Brazil.

\section{General experimental procedures}

The essential oils were submitted to qualitative analysis by NMR and GC-MS, while quantitative analysis was performed by gas chromatography with flame ionization detector (GC-FID).

The ${ }^{1} \mathrm{H}$ and ${ }^{13} \mathrm{C}$ NMR were obtained on Bruker spectrometers, Avance DRX-500 (500 MHz for ${ }^{1} \mathrm{H}$ and $125 \mathrm{MHz}$ for ${ }^{13} \mathrm{C}$ ) or DPX-300 (300 MHz for ${ }^{1} \mathrm{H}$ and $75 \mathrm{MHz}$ for ${ }^{13} \mathrm{C}$ ), proton chemical shifts were referenced to the residual undeuterated $\mathrm{CHCl}_{3}\left(\delta_{\mathrm{H}} 7.27\right)$, while the center peak of the deuterated $\mathrm{CDCl}_{3}\left(\delta_{\mathrm{C}} 77.23\right)$ was used to reference the $\mathrm{C}-13$ spectra.

Similar chromatographic conditions were used for qualitative GC-MS (Shimadzu GCMS-QP2010-Plus) and quantitative GC-FID (Shimadzu GC-2010-FI) analysis: fused-silica capillary column RTx-5 (30 m × $0.25 \mathrm{~mm}$ i.d., $0.25 \mu \mathrm{m}$ film thickness); injections in splitless mode with injection temperature of $220{ }^{\circ} \mathrm{C}$; the column was programmed from 60 to $240{ }^{\circ} \mathrm{C}$ at $3{ }^{\circ} \mathrm{C} \mathrm{min}-1$ and held isothermal for $7 \mathrm{~min}$. Helium and hydrogen $\left(\mathrm{H}_{2}\right)$ were used as carrier gas to GC-MS and GC-FID analysis, respectively, at $1.0 \mathrm{~mL} \mathrm{~min}{ }^{-1}$ flow rate. The interface temperature of GC-MS was $240{ }^{\circ} \mathrm{C}$ and the mass spectra were recorded from $30-450 \mathrm{~m} / \mathrm{z}$, under a scan interval of $0.5 \mathrm{~s}$, with electron impact ionization voltage of $70 \mathrm{eV}$.

Each component was identified by comparison of the acquired mass spectrum with reference data from a commercially available database (NIST 2.0) and those described by Adams, ${ }^{8}$ as well as by its experimental Kovats retention index (KI) calculated from a C9-C24 $n$-alkanes series.

\section{Essential oil distillation}

Essential oils from the entire fresh leaves of M. urundeuva, or fresh leaves crushed (T) in a semi- industrial blender (without water) and blended with water (TW) were obtained by hydrodistillation, over a period of $2 \mathrm{~h}$, in a Clevenger-type apparatus modified by Gottlieb and Magalhães. ${ }^{9}$ The oils were dried over $\mathrm{Na}_{2} \mathrm{SO}_{4}$, stored in glass vials and preserved under refrigeration before analysis. The yields of the obtained oils were calculated by the ratio of oil volume obtained and fresh weight of plant materials. 62 specimens of "aroeira-do-sertão" were analyzed and the acquired experimental data are shown in Table S1.

\section{Results and Discussion}

Several works in the literature about plant essential oils, report the volatile chemical composition for a single specimen, therefore, defining the chemical composition of a particular species, such as the recent cases of Anacardium humile, ${ }^{7}$ Lithraea molleoides ${ }^{10}$ and Astronium graveolens. ${ }^{11}$ In order to get adapted to the climate, soil type, altitude and other conditions of a region, a plant is able to modify its chemical composition without affecting significantly its phenotypic characteristics. Thus, to be adapted to a particular environment a plant can lead to chemically new specimens with identical or very similar morphological characteristics of the parent ones. Chemotypes are specimens of the same species that show differences in secondary metabolism, varying either the chemical structure or its quantitative composition. Chemical studies of these species cannot be disregarded because the factors aforementioned can directly affect their pharmacological properties. Active principles may be different regarding to its chemical structure and relative concentrations between different chemotypes of the same species. ${ }^{12}$

This paper reports the study of the volatile chemical composition of leaves from 62 specimens of "aroeirado-sertão" collected in five states in northeastern Brazil [Ceará (32), Rio Grande do Norte (17), Bahia (4), Pernambuco (4) and Piauí (5)] (Table S1 and Figure S19, Supplementary Information).

The essential oils from fresh leaves obtained by hydrodistillation process using a Clevenger apparatus, modified by Gottlieb and Magalhães, ${ }^{9}$ have yields ranging from 0.05 to $0.36 \% \mathrm{~m} / \mathrm{v}$ (Table $\mathrm{S} 1$ ). The first essential oils (CE-1, CE-2, CE-3 and CE-4) qualitatively analyzed by NMR and GC-MS exhibited very interesting results, because the ${ }^{1} \mathrm{H}$ NMR spectra and chromatograms showed almost a single constituent, but with different chemical structures (Table S1). The CE-1 and CE-2 specimens revealed ( $Z$ )- $\beta$-ocimene, CE-3 $\Delta^{3}$-carene, while CE-4 presented $\alpha$-pinene as the major constituent. These results stimulated the continuation, and expansion, of the study of 
essential oils from "aroeira-do-sertão" leaves, requiring a wider range of individual specimens from different regions.

Leaves of 62 individual specimens (Table S1) were collected in five different states of northeastern Brazil. ${ }^{1} \mathrm{H}$ and ${ }^{13} \mathrm{C}$ NMR spectrum analysis of the essential oils resulted in structure elucidation of different constituents for each sample, allowing the classification of the 62 samples into six distinct groups characterized by the production of a major constituent: $\Delta^{3}$-carene (21 samples), $(Z)-\beta$-ocimene (7 samples), $(E)$ - $\beta$-ocimene (7 samples), $\alpha$-pinene (10 samples), myrcene (4 samples) and limonene (13 samples).

GC-MS chromatograms and ${ }^{1} \mathrm{H}$ NMR spectra (in triplicates), representatives of crude oils for each major constituent are illustrated in Figure 1, and Figures S1 to S18 (Supplementary Information), respectively. Comparison of the ${ }^{13} \mathrm{C}$ NMR data of the six chemotypes with literature data ${ }^{13,14}$ are shown in Table S2 (Supplementary Information). Analysis of ${ }^{1} \mathrm{H}$ NMR spectra (Figures S1-S18) showed the presence of almost a single major compound and, because NMR is a very diagnostic technique, the characterization of the major constituent could be easily determined. ${ }^{1} \mathrm{H}$ NMR spectra for the six major compounds are readily distinguished, because the characteristic signals of each monoterpene like the number of methyl groups and the number of carbon-carbon double bonds, among others, allow rapid identification of the chemotypes.
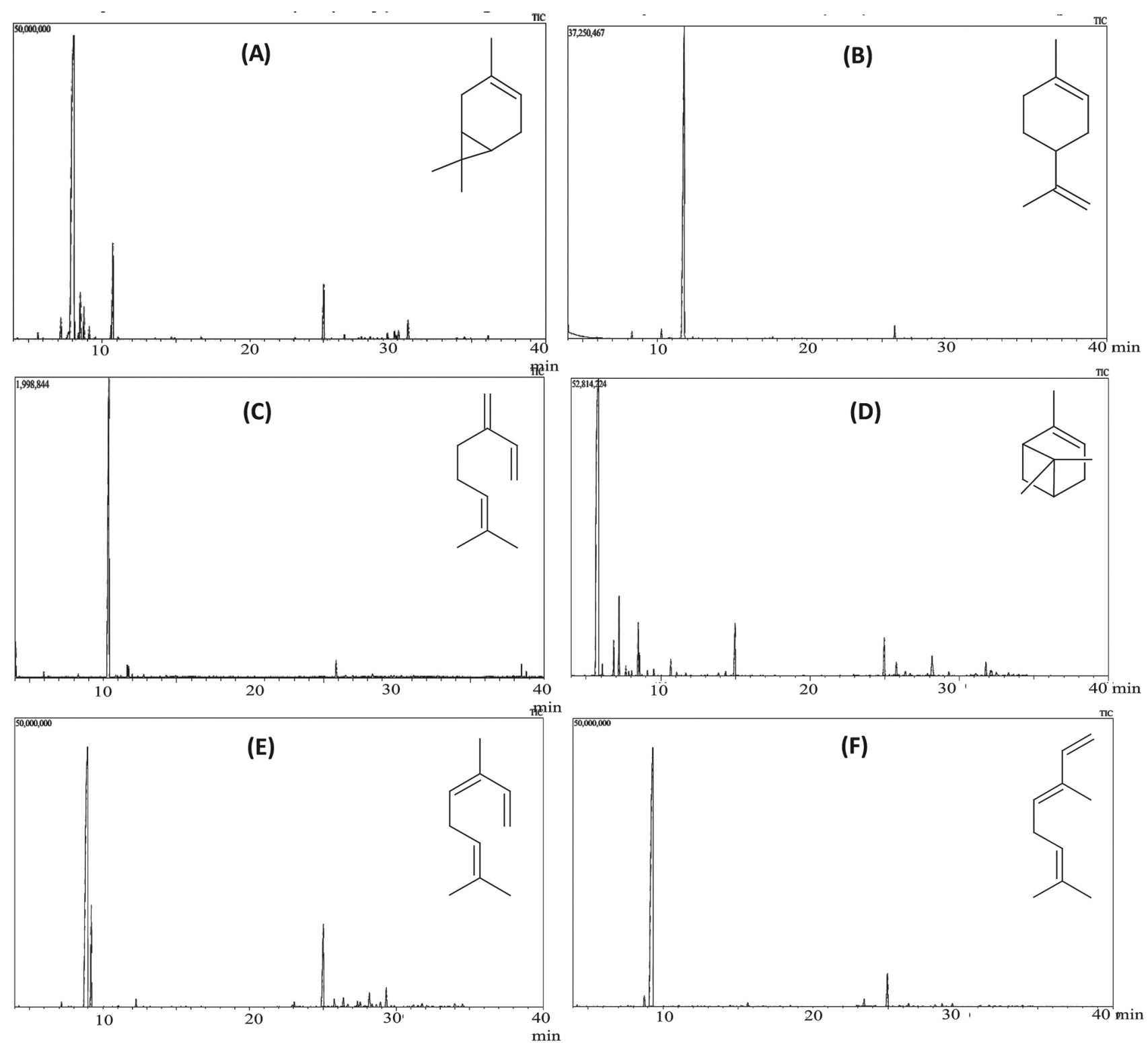

Figure 1. Chromatograms obtained by GC-MS, with structures of each major constituent of the crude essential oils samples from M. urundeuva (chemotypes: (A) $\Delta^{3}$-carene; (B) limonene; (C) myrcene; (D) $\alpha$-pinene; (E) (Z)- $\beta$-ocimene and (F) $(E)$ - $\beta$-ocimene). 
Qualitative identification and quantification of the minor constituents of the essential oils were made by GC-MS and GC-FID, respectively. The results of these analyzes for the six representative specimens are shown in Table 1.

The chemical composition of the essential oils of the studied specimens consists of mono and sesquiterpenes and shows just a major constituent. All major compounds present in the different specimens exhibited yields always around $79 \%$ or higher (Table 1, bold values).

Analyses by GC-MS and GC-FID (Table 1) also showed that among the sesquiterpenes identified in the oils obtained from whole leaves, $(E)$-caryophyllene was the only one common to all specimens, always in higher amounts (1.57 to $8.32 \%$ ).

In order to determine a possible seasonal variation, the leaves were collected from the same eight specimens of "aroeira-do-sertão" (CE-2, CE-3, CE-4, CE-8, CE-9, RN-2,
RN-7 and RN-8) in different seasons. The analyses of oils were monitored by ${ }^{1} \mathrm{H}$ NMR. The selected samples were analyzed in different months of the same year (CE-2 and CE-3); in the same month, but in different years (CE-4 and $\mathrm{RN}-2$ ); in the same month and year (CE-8 and CE-9); and for different months at different years (RN-7 and RN-8). The constitution of the essential oils of these chosen plants did not show any significant difference in the concentration of the major constituent during the whole study (Table S1).

To analyze the influence of the methodology used in the chemical composition of the essential oils, leaves from specimens of "aroeira-do-sertão" were collected on the same day, CE-2 to CE-4 and RN-2, corresponding to chemotypes, (Z)- $\beta$-ocimene and $\alpha$-pinene and myrcene, respectively. Each material was submitted to two different extraction procedures: in the first case, the leaves were simply crushed (T) in a semi-industrial blender (without

Table 1. GC-MS and GC-FID data of the essential oils from whole fresh leaves of six representative specimens of wild "aroeira-do-sertão"

\begin{tabular}{|c|c|c|c|c|c|c|c|c|c|c|c|c|c|}
\hline \multirow[t]{2}{*}{ Compound } & \multirow[t]{2}{*}{$\mathrm{KI}^{8}$} & \multicolumn{2}{|c|}{$\begin{array}{c}\text { CE-3 } \\
\Delta^{3} \text {-carene }\end{array}$} & \multicolumn{2}{|c|}{$\begin{array}{c}\text { RN8 } \\
\text { limonene }\end{array}$} & \multicolumn{2}{|c|}{$\begin{array}{c}\mathrm{RN}-2 \\
\text { myrcene }\end{array}$} & \multicolumn{2}{|c|}{$\begin{array}{c}\text { CE-4 } \\
\alpha \text {-pinene }\end{array}$} & \multicolumn{2}{|c|}{$\begin{array}{c}\text { CE-2 } \\
(Z)-\beta \text {-ocimene }\end{array}$} & \multicolumn{2}{|c|}{$\begin{array}{c}\text { CE-32 } \\
(E)-\beta \text {-ocimene }\end{array}$} \\
\hline & & $\mathrm{KIc}^{\mathrm{a}}$ & $\%$ & $\mathrm{KIc}^{\mathrm{b}}$ & $\%$ & $\mathrm{KIc}^{\mathrm{c}}$ & $\%$ & $\mathrm{KIc}^{\mathrm{d}}$ & $\%$ & $\mathrm{KIc}^{\mathrm{e}}$ & $\%$ & $\mathrm{KIc}^{\mathrm{f}}$ & $\%$ \\
\hline$\alpha$-Pinene & 939 & 939 & 0.25 & 950 & 1.97 & 951 & 0.33 & 958 & 87.85 & - & - & - & - \\
\hline Canfene & 946 & - & - & - & - & - & - & 964 & 0.28 & - & - & - & - \\
\hline$\beta$-Pinene & 979 & - & - & - & - & - & - & 982 & 1.42 & - & - & - & - \\
\hline Myrcene & 990 & 990 & 0.95 & 1001 & 1.52 & 990 & 88.13 & 991 & 1.82 & 1005 & 0.25 & - & - \\
\hline$\Delta^{3}$-Carene & 1011 & 1011 & 84.52 & - & - & - & - & 1006 & 0.22 & - & - & - & - \\
\hline$\alpha$-Terpinene & 1017 & 1017 & 0.36 & - & - & - & - & - & - & - & - & - & - \\
\hline Limonene & 1029 & - & - & 1014 & 92.96 & 1020 & 1.30 & 1022 & 1.49 & - & - & - & - \\
\hline Sylvestrene & 1030 & 1030 & 2.18 & - & - & - & - & - & - & - & - & - & - \\
\hline Eucaliptol & 1031 & - & - & - & - & 1022 & 0.56 & 1024 & 0.43 & - & - & - & - \\
\hline$(Z)-\beta$-Ocimene & 1037 & 1032 & 1.05 & - & - & 1026 & 0.20 & - & - & 1047 & 79.17 & 1034 & 1.20 \\
\hline (E)- $\beta$-Ocimene & 1050 & 1050 & 0.41 & - & - & - & - & - & - & 1052 & 5.95 & 1047 & 91.46 \\
\hline Terpinolene & 1088 & 1088 & 4.07 & - & - & 1045 & 0.36 & 1074 & 0.43 & - & - & - & - \\
\hline$\alpha$-Copaene & 1376 & - & - & - & - & - & - & - & - & 1375 & 0.32 & - & - \\
\hline E-Caryophyllene & 1419 & 1419 & 2.54 & 1419 & 2.01 & 1415 & 3.97 & 1419 & 1.57 & 1421 & 8.32 & 1419 & 3.54 \\
\hline Aromadendrene & 1441 & - & - & - & - & 1433 & 0.34 & 1438 & 0.57 & 1438 & 0.65 & - & - \\
\hline$\alpha$-Humulene & 1454 & 1454 & 0.19 & - & - & 1448 & 0.36 & - & - & 1452 & 0.66 & 1454 & 0.30 \\
\hline$\gamma$-Muurolene & 1479 & - & - & - & - & - & - & - & - & 1475 & 0.40 & - & - \\
\hline Germacrene D & 1481 & - & - & - & - & - & - & - & - & 1479 & 0.36 & - & - \\
\hline Viridiflorene & 1496 & - & - & - & - & 1490 & 0.80 & 1495 & 0.18 & 1496 & 1.31 & - & - \\
\hline$\delta$-Cadinene & 1523 & 1522 & 0.25 & - & - & 1518 & 0.29 & - & - & 1520 & 1.45 & 1521 & 0.23 \\
\hline Selina-3,7(11)-diene & 1546 & 1546 & 0.35 & - & - & 1535 & 0.31 & - & - & - & - & - & - \\
\hline Germacrene B & 1561 & 1561 & 0.77 & - & - & 1551 & 0.60 & - & - & - & - & - & - \\
\hline Viridiflorol & 1592 & - & - & - & - & 1577 & 0.25 & 1582 & 0.63 & - & - & - & - \\
\hline Total identified / \% & & \multicolumn{2}{|c|}{97.89} & \multicolumn{2}{|c|}{98.46} & \multicolumn{2}{|c|}{97.80} & \multicolumn{2}{|c|}{96.89} & \multicolumn{2}{|c|}{98.84} & \multicolumn{2}{|c|}{96.73} \\
\hline
\end{tabular}

KI: Kovats index; KIc: Kovats indices calculated through the equation. ${ }^{a} \mathrm{KIc}=24.26 \mathrm{Tr}+814 ;{ }^{\mathrm{b}} \mathrm{KIc}=24.37 \mathrm{Tr}+808 ;{ }^{\mathrm{c}} \mathrm{KIc}=23.90 \mathrm{Tr}+818 ;{ }^{\mathrm{d}} \mathrm{KIc}=24.07 \mathrm{Tr}+818$; ${ }^{\mathrm{e}} \mathrm{KIc}=23.23 \mathrm{Tr}+839 ;{ }^{\mathrm{f}} \mathrm{KIc}=23.73 \mathrm{Tr}+826$. 
water) and, in the other case, the leaves were blended with water (TW) generating a leaf "juice". After this, both were subjected to the hydrodistillation process. After determining the yield, the essential oils were analyzed by ${ }^{1} \mathrm{H}$ NMR, GC-MS and GC-FID (Table 2).

The data obtained for the essential oils from crushed leaves $(\mathrm{T})$ showed that, for all samples, the yield of the principal monoterpene decreased considerably (Table 2) as compared to those obtained from whole leaves (Table 1), while the amount of the sesquiterpene $(E)$-caryophyllene increased. In the case of the triturated leaves with water (TW), for samples CE-2, CE-4 and RN-2, the major constituent percentage was even lower, and yet were identified novel compounds, not previously observed for the whole leaf as is the case of the $(E)$-hex-2-enal, (Z)-hex-3-enol and (Z)-hex-2-enol. It was also observed that for the triturated leaves, $\alpha$-humulene, $\delta$-cadinene and $(E)$-caryophyllene are common to the essential oils from all the studied specimens (Table 2).

The decrease of monoterpenes and increase of sesquiterpenes [mainly $(E)$-caryophyllene] in the chemical composition of the oils generated from triturated leaves can be justified by the alterations of the leaves during the grinding process. During grinding occurs the break-up

Table 2. GC-MS and GC-FID data of the essential oils from individual wild specimens of "aroeira-do-sertão" extracted from crushed fresh leaves (T), and from fresh leaves blended with water (TW) of four different chemotypes

\begin{tabular}{|c|c|c|c|c|c|c|c|c|c|c|c|c|c|c|c|c|c|}
\hline \multirow{3}{*}{ Compounds } & \multirow{3}{*}{$\mathrm{KI}^{8}$} & \multicolumn{4}{|c|}{ CE-3 ( $\Delta^{3}$-carene $)$} & \multicolumn{4}{|c|}{ RN-2 (myrcene) } & \multicolumn{4}{|c|}{ CE-4 (limonene) } & \multicolumn{4}{|c|}{ CE-2 $[(Z)-\beta$-ocimene $]$} \\
\hline & & \multicolumn{2}{|c|}{$\mathrm{T}$} & \multicolumn{2}{|c|}{ TW } & \multicolumn{2}{|c|}{$\mathrm{T}$} & \multicolumn{2}{|c|}{ TW } & \multicolumn{2}{|c|}{$\mathrm{T}$} & \multicolumn{2}{|c|}{ TW } & \multicolumn{2}{|c|}{$\mathrm{T}$} & \multicolumn{2}{|c|}{ TW } \\
\hline & & $\mathrm{KIc}^{\mathrm{a}}$ & $\%$ & $\mathrm{KIc}^{\mathrm{b}}$ & $\%$ & $\mathrm{KIc}^{\mathrm{c}}$ & $\%$ & $\mathrm{KIc}^{\mathrm{d}}$ & $\%$ & $\mathrm{KIc}^{\mathrm{e}}$ & $\%$ & $\mathrm{KIc}^{\mathrm{f}}$ & $\%$ & $\mathrm{KIc}^{\mathrm{g}}$ & $\%$ & $\mathrm{KIc}^{\mathrm{h}}$ & $\%$ \\
\hline (E)-Hex-2-enal & 855 & 917 & 1.94 & 912 & 3.63 & 904 & 3.33 & 904 & 1.03 & 889 & 2.30 & 893 & 2.66 & 874 & 2.54 & 916 & 1.42 \\
\hline (Z)-Hex-3-enol & 859 & 918 & 3.19 & 913 & 1.02 & 906 & 3.05 & 906 & 0.95 & 892 & 2.00 & 895 & 0.60 & 877 & 2.13 & 917 & 1.88 \\
\hline (Z)-Hex-2-enol & 862 & 922 & 1.01 & - & - & 910 & 1.49 & 911 & 0.81 & - & - & - & - & 879 & 0.95 & 921 & 0.90 \\
\hline$\alpha$-Pinene & 939 & - & - & - & - & 953 & 0.41 & - & - & 938 & 68.40 & 938 & 35.73 & - & - & - & - \\
\hline Myrcene & 990 & - & - & 992 & 0.53 & 988 & 67.48 & 986 & 30.00 & 914 & 2.11 & 977 & 1.93 & - & - & - & - \\
\hline$\Delta^{3}$-Carene & 1011 & 1014 & $\mathbf{5 3 . 8 7}$ & 1009 & 54.07 & - & - & - & - & - & - & - & - & - & - & - & - \\
\hline$\alpha$-Terpinene & 1017 & 1017 & 1.80 & - & - & - & - & - & - & - & - & - & - & - & - & - & - \\
\hline Limonene & 1029 & - & & - & & 1017 & 1.45 & 1017 & 0.83 & 1016 & 2.29 & 1019 & 2.25 & - & & - & - \\
\hline Eucaliptol & 1031 & - & - & - & - & 1020 & 0.49 & - & - & 1018 & 0.67 & 1021 & 0.67 & - & - & - & - \\
\hline Sylvestrene & 1030 & 1027 & 0.92 & 1023 & 1.85 & - & - & - & - & - & - & - & - & - & - & - & - \\
\hline (Z)- $\beta$-Ocimene & 1037 & - & - & 1029 & 0.97 & - & - & - & - & - & - & - & - & 1025 & 60.75 & 1035 & 57.15 \\
\hline$(E)$ - $\beta$-Ocimene & 1050 & - & - & 1038 & 0.51 & - & - & - & - & - & - & - & - & 1040 & 5.33 & 1042 & 522 \\
\hline Terpinolene & 1088 & 1079 & 4.86 & 1076 & 5.38 & - & - & - & - & - & - & - & - & - & - & - & - \\
\hline$\alpha$-Copaene & 1376 & - & - & 1373 & 0.53 & - & - & - & - & - & - & - & - & 1368 & 0.62 & 1373 & 0.69 \\
\hline$E$-Caryophyllene & 1419 & 1421 & 14.91 & 1421 & 15.32 & 1420 & 11.53 & 1419 & 31.37 & 1420 & 5.79 & 1420 & 13.92 & 1420 & 14.55 & 1421 & 17.18 \\
\hline Aromadendrene & 1441 & - & - & - & - & 1437 & 0.72 & 1436 & 2.06 & 1439 & 1.48 & 1440 & 3.30 & 1438 & 0.69 & 1438 & 0.88 \\
\hline$\alpha$-Humulene & 1454 & 1454 & 1.28 & 1453 & 1.23 & 1452 & 1.00 & 1453 & 2.75 & 1454 & 0.67 & 1455 & 1.66 & 1454 & 1.29 & 1453 & 1.56 \\
\hline$\gamma$-Muurolene & 1479 & - & - & - & - & - & - & - & - & 1500 & 3.81 & - & - & 1479 & 0.55 & 1476 & 0.69 \\
\hline Germacrene D & 1481 & 1481 & 0.91 & 1481 & 0.86 & - & - & - & - & - & - & - & - & 1484 & 1.22 & 1481 & 1.19 \\
\hline Viridiflorene & 1496 & - & - & 1495 & 0.52 & 1495 & 1.36 & 1494 & 2.82 & - & - & 1500 & 6.84 & 1500 & 2.39 & 1495 & 2.48 \\
\hline$\gamma$-Cadinene & 1513 & - & - & - & - & - & - & - & - & - & - & - & - & 1519 & 0.44 & 1513 & 0.57 \\
\hline$\delta$-Cadinene & 1523 & 1523 & 1.47 & 1523 & 1.29 & 1523 & 0.95 & 1523 & 2.42 & 1527 & 0.73 & 1527 & 1.87 & 1529 & 2.36 & 1522 & 3.03 \\
\hline Selina-3,7(11)-diene & 1546 & 1541 & 0.86 & 1541 & 0.81 & 1540 & 0.52 & 1541 & 1.50 & - & - & - & - & - & - & - & - \\
\hline Germacrene B & 1561 & 1557 & 7.66 & 1558 & 6.75 & 1557 & 2.22 & 1558 & 7.10 & - & - & - & - & - & - & - & - \\
\hline Spathulenol & 1578 & - & - & - & - & - & - & - & - & - & - & - & - & - & - & - & - \\
\hline Viridiflorol & 1592 & - & - & - & - & 1582 & 0.40 & 1583 & 2.50 & 1590 & 0.60 & 1590 & 6.30 & 1600 & 0.86 & 1589 & 1.13 \\
\hline$\alpha$-Cadinol & 1654 & 1647 & 0.66 & 1649 & 0.45 & - & - & - & - & - & - & - & - & 1663 & 0.64 & 1647 & 0.89 \\
\hline Total identified / \% & & 95.34 & & 95.72 & & 96.40 & & 86.14 & & 90.85 & & 77.73 & & 97.31 & & 96.86 & \\
\hline
\end{tabular}

KI: Kovats index; KIc: Kovats indices calculated through equation. ${ }^{\mathrm{a}} \mathrm{KIc}=23.80 \mathrm{Tr}+826 ;{ }^{\mathrm{b}} \mathrm{KIc}=24.01 \mathrm{Tr}+820 ;{ }^{\mathrm{c}} \mathrm{KIc}=24.25 \mathrm{Tr}+812 ;{ }^{\mathrm{d}} \mathrm{KIc}=24.29 \mathrm{Tr}+812$; ${ }^{\mathrm{e}} \mathrm{KIc}=24.97 \mathrm{Tr}+795 ;{ }^{\mathrm{f}} \mathrm{KIc}=24.86 \mathrm{Tr}+799 ;{ }^{\mathrm{g}} \mathrm{KIc}=25.67 \mathrm{Tr}+777 ;{ }^{\mathrm{h}} \mathrm{KIc}=23.85 \mathrm{Tr}+824$. 
of the trichomes ("pockets" where the essential oils are encapsulated in plants). In the case of extraction from entire leaves the trichomes cleavage only occurs during heating, while the earlier rupture of the trichomes through the previous grinding can lead to the loss of the more volatile constituents (monoterpenes) before the hydrodistillation process.

\section{Conclusions}

This is the first report for the existence of different chemotypes for Myracrodruon urundeuva species of northeastern Brazil. The analysis of 62 samples of essential oils from leaves of wild M. urundeuva allowed the identification of six major monoterpenes as chemical markers and, consequently, the characterization of six different chemotypes, revealing a higher level of intraspecific chemical variation for this species. It was also shown that the production of the major constituent of each specimen, of each different chemotype, is constant and independent of the time of harvesting, the year season and of the influence of their habitat (soil and climate conditions). It was also observed that essential oils extracted from entire leaves, crushed leaves (in a blender without water), or blended leaves (with water) showed different yield and different chemical composition. Moreover, grinding (blending with or without water) decreases drastically the oil yield, while the composition of the less volatile sesquiterpenes are increased in comparison to monoterpenes. The ${ }^{13} \mathrm{C}$ NMR data of $(E)$ - $\beta$-ocimene is being reported for the first time in the chemical literature.

This study calls attention to the need for more detailed studies on the volatile composition of higher plants already reported in the literature, particularly for those with a tree size, taking in consideration the possibility of extracting entire or crushed leaves of individual specimens in order to detect the possibility, or not, of the occurrence of different chemotypes.

Another aspect that needs to be emphasized is the fact that, as can be seen from Table 1, the major constituent co-exist with several other chemomarkers, for instance, $\alpha$-pinene $(0.25 \%)$, myrcene $(0.95 \%),(Z)$ - $\beta$-ocimene $(1.05 \%)$ and $(E)$ - $\beta$-ocimene $(0.41 \%)$ are all together with $\Delta^{3}$-carene $(84.52 \%)$ in CE-3 sample. This shows the higher degree of specialization of the enzymatic system of M. urundeuva to produce exclusively that major compound, which would be a challenge field for exploration by chemists and biochemists.

Surprisingly, the major component is always the same independently of the time of harvesting like it has been observed for $\mathrm{RN}-2$ samples.

\section{Supplementary Information}

Supplementary data are available free of charge at http://jbcs.sbq.org.br as PDF file.

\section{Acknowledgments}

The authors are grateful to CNPq, CAPES, FUNCAP and PRONEX for the fellowships and financial support.

\section{References}

1. Lorenzi, H.; Matos, F. J. A.; Plantas Medicinais no Brasil Nativas e Exóticas; Instituto Plantarum de Estudos da Flora LTDA: Nova Odessa, Brasil, 2000.

2. Viana, G. S. B.; Bandeira, M. A. M.; Matos, F. J. A.; Phytomedicine 2003, 10, 189.

3. Matos, F. J. A.; Farmácias Vivas: Sistemas de Utilização de Plantas Medicinais Projetado para Pequenas Comunidades; UFC: Fortaleza, Brasil, 2002.

4. Braga, R.; Plantas do Nordeste Especialmente do Ceará; Escola Superior de Agricultura: Mossoró, Brasil, 2001.

5. Maia, J. G. S.; Silva, M. H. L.; Andrade, E. H. A.; Zoghbi, M. G. B.; Carreira, L. M. M.; Flavour Fragrance J. 2002, 17, 72.

6. Montanari, R. M.; Barbosa, L. C. A.; Demuner, A. J.; Silva, C. J.; Andrade, N. J.; Ismail, F. M. D.; Barbosa, M. C. A.; Molecules 2012, 17, 9728.

7. Figueredo, F. G.; Lucena, B. F. F.; Tintino, S. R.; Matias, E. F. F.; Leite, N. F.; Andrade, J. C.; Nogueira, L. F. B.; Morais, E. C.; Costa, J. G. M.; Coutinho, H. D. M.; Rodrigues, F. F. G.; Pharm. Biol. 2014, 52, 560.

8. Adams, R. P.; Identification of Essential Oil Components by Gas Chromatography/Mass Spectroscopy; Allured Publishing Corporation: Carol Stream, Illinois, USA, 2001.

9. Gottlieb, O. R.; Magalhães, M. T.; Chem. Anal. 1960, 49, 114.

10. Shimizu, M. T.; Bueno, L. J. F.; Rodrigues, R. F. O.; Sallowicz, F. A.; Frankl, A. C. H. S.; Maio, M. O.; Braz. J. Microbiol. 2006, 37, 556 .

11. Burbano, D. R.; Celis, C. E. Q.; Pino, J. A.; J. Essent. Oil Res. 2010, 6, 488 .

12. Polatoglu, K.; The Nat. Prod. J. 2013, 3, 10.

13. Chang, C. W. J.; Flament, I.; Matson, J. A.; Nishida, T.; Ohloff, G.; Wehrli, F. W.; Weinheimer, A. J.; Progress in the Chemistry of Organic Natural Products, vol. 36; Herz, W.; Grisebach, H.; Kirby, G. W., eds.; Springer-Verlag: New York, USA, 1979.

14. Pouchert, C. J.; Behnke, J.; The Aldrich Library of ${ }^{13} \mathrm{C}$ and ${ }^{1} H$ FT-NMR Spectra, vol. 1, $1^{\text {st }}$ ed.; Aldrich Chemical Co.: Milwaukee, 1983.

Submitted: June 27, 2016

Published online: August 24, 2016 